\title{
ATENDIMENTO EDUCACIONAL ESPECIALIZADO NA REDE MUNICIPAL DE UBERLÂNDIA: IMPLANTAÇÃO, ORGANIZAÇÃO E DESENVOLVIMENTO
}

\author{
ATENCIÓN EDUCATIVA ESPECIALIZADA EN LA RED MUNICIPAL DE \\ UBERLAND: IMPLEMENTACIÓN, ORGANIZACIÓN Y DESARROLLO
}

\section{SPECIALIZED EDUCATIONAL CARE IN THE UBERLAND MUNICIPAL NETWORK: IMPLEMENTATION, ORGANIZATION AND DEVELOPMENT}

\author{
Carla BARBOSA ALVES ${ }^{1}$ \\ Maria Irene MIRANDA ${ }^{2}$
}

\begin{abstract}
RESUMO: Esta pesquisa teve como objetivo descrever e analisar a proposta de trabalho do Atendimento Educacional Especializado (AEE) das escolas municipais do município de Uberlândia-MG. Para tanto, foi realizada uma pesquisa qualitativa de caráter descritivo e analítico, como definem Lüdke e André (1986), por ser um espaço singular de análise de uma situação do cotidiano, em que lançamos mão do referencial teórico, da prática e da reflexão. Por meio da construção dos dados foi possível fazer a correlação de todos os aspectos apresentados pelos atores da pesquisa, o que culminou em quatro categorias: a história da Educação Especial no município; a visão dos professores do AEE e da sala/classe comum sobre o AEE e o NADH; Sala de Recurso Multifuncional (SRM) e acessibilidade arquitetônica e pedagógica; e a formação de professores. A pesquisa explicitou a necessidade da interlocução entre professores do AEE e da sala/classe comum, bem como uma formação continuada dos professores. Constatamos que as escolas da rede municipal têm se articulado para a oferta do AEE, mas muito ainda precisa ser realizado para esse intento.
\end{abstract}

PALAVRAS-CHAVE: Inclusão. Educação especial. Atendimento Educacional especializado.

RESUMEN: Esta investigación tuvo como objetivo describir y analizar la propuesta de trabajo de la Asistencia Educativa Especializada (AEE) de las escuelas municipales de Uberlândia-MG. Por lo tanto, se realizó una investigación cualitativa descriptiva y analítica, según lo definido por Lüdke y André (1986), ya que es un espacio único para el análisis de una situación cotidiana, en el que utilizamos el marco teórico, la práctica y la reflexión. Mediante la construcción de datos fue posible correlacionar todos los aspectos presentados por los actores de la investigación, que culminaron en cuatro categorías: la historia de la Educación Especial en el municipio; la opinión de los maestros de ESA y la clase / sala común sobre ESA y NADH; Sala de Recursos Multifuncionales (SRM) y accesibilidad

\footnotetext{
${ }^{1}$ Prefeitura Municipal de Uberlândia (PMU), Uberlândia - MG - Brasil. Coordenadora de Ensino da Educação Especial. Mestre em educação: Educação Especial pela Universidade Federal de Uberlândia. Especialista em Metodologia do Ensino Superior, Educação Especial, ambos pela UFU, e em Atendimento Educacional Especializado pela UFC. ORCID: https://orcid.org/0000-0002-3781-7191. E-mail: carlabarbosa180@gmail.com ${ }^{2}$ Universidade Federal de Uberlândia (UFU), Uberlândia - MG - Brasil. Professora efetiva da Faculdade de Educação (graduação e pós-graduação). Doutora em Educação pela Pontifícia Universidade Católica de São Paulo. Possui graduação em Pedagogia pela UFU, especialização em Psicopedagogia pela UFU e mestrado em Educação pela UFU. Coordenadora do GEPPE (Grupo de Estudos e Pesquisa sobre a Psicopedagogia Escolar), coordenadora do Curso de Especialização em Psicopedagogia. ORCID: https://orcid.org/0000-0002-2918-8524. E-mail: mirenemufu@gmail.com
} 
arquitectónica y pedagógica; y formación docente. La investigación aclaró la necesidad de un diálogo entre los docentes de la ESA y la sala / clase común, así como una educación continua de los docentes. Descubrimos que las escuelas de la red municipal se han estado articulando para la oferta de la ESA, pero aún queda mucho por hacer para este propósito.

PALABRAS CLAVE: Inclusión. Educación especial. Servicio Educativo Especializado.

ABSTRACT: This study aimed to describe and analyze the proposed work of the Educational Service Specialist (ESA) of municipal schools in the city of Uberlândia-MG. For this, a qualitative study of descriptive and analytical character was held, as defined by Lüdke and André (1986), because it is a singular space of analysis of a situation of daily life, in which we use theoretical reference, practice and reflection. By building of the data was possible to make the correlation of all aspects presented by the actors of the research, which culminated in four categories: the special education history in the city; ESA teachers of vision and living/class over the AEE and NADH; Multifunctional Resource Room (SRM) and architectural and pedagogical accessibility; and teacher training. The survey indicated the need for dialogue between ESA teachers and the living/dining-class as well as continued training of teachers. We note that municipal schools have articulated for the provision of the ESA, but much remains to be done for this purpose.

KEYWORDS: Inclusion. Special Education. Specialized Education Attendance.

\section{A Educação Especial na Perspectiva da Educação Inclusiva}

A escola tem sido desafiada cada vez mais ao receber pessoas com deficiência em seu contexto. A proposta de educação inclusiva tem exigido a reestruturação das escolas e a modificação das práticas pedagógicas desenvolvidas nesse espaço. Com a educação inclusiva, a Educação Especial tem se ressignificado ao longo dos tempos e, principalmente, nesta última década com a nova Política de Educação Especial na Perspectiva da Educação Inclusiva de 2008.

Considerando toda a nossa trajetória e, em específico, o trabalho realizado com os alunos com deficiência desde 2005, uma das nossas maiores inquietações, e que também é dúvida de muitos, está em como implantar e organizar o Atendimento Educacional Especializado (AEE) nas escolas. A escola e os professores ainda têm muitas dúvidas em como garantir o acesso e permanência desses alunos com qualidade. Daí, então, o enfoque deste trabalho que se propõe a descrever e analisar a organização, a implantação e o desenvolvimento desse atendimento no município de Uberlândia, tendo como parâmetro os documentos orientadores para esse serviço.

Mediante o referido contexto, o nosso estudo, então, teve por objetivo descrever e analisar a proposta de trabalho do AEE implantado e desenvolvido pela Secretaria Municipal de Educação de Uberlândia (SME) de 2005 a 2014, para os alunos público-alvo da Educação 
Especial, matriculados nas escolas municipais de Ensino Fundamental do $1 .^{\circ}$ ao $5 .^{\circ}$ ano, à luz dos documentos oficiais que regulamentam as ações para esse atendimento no Brasil.

O período de 2005 a 2014 foi assim definido pelo fato de a construção da Política Nacional de Educação Especial na Perspectiva da Educação Inclusiva (2008), que vigora até os dias atuais, ter iniciado suas discussões em 2005 e o município de Uberlândia ter começado a ressignificar esse atendimento nesse período. Um dos focos dessa política é a implantação do AEE como atendimento complementar e/ou suplementar ao trabalho desenvolvido com os alunos com deficiência na classe comum, oferecendo o que lhes é necessário para a sua promoção e verdadeiro aprendizado.

O problema desta pesquisa perpassou pelas seguintes questões: Como está sendo realizado o atendimento (complementar e/ou suplementar) dos alunos com deficiência e a organização das Salas de Recursos Multifuncionais (SRM). Como tem sido assegurada a acessibilidade arquitetônica e pedagógica desses alunos? Como tem se dado a formação dos professores do AEE?

Em consonância com o objetivo de pesquisa, e ao se pensar em uma pesquisa em educação, chegamos à abordagem qualitativa de caráter descritivo e analítico. Assim, a pesquisa desenvolvida partiu de uma realidade inserida em um dado contexto histórico e social, e "a investigação qualitativa exige que se enxergue o mundo com a ideia de que nada é trivial, porém tudo tem potencial para constituir uma pista que permita estabelecer uma compreensão do objeto de estudo" (BOGDAN; BIKLEN, 1994, p. 49). Utilizamos como procedimentos metodológicos a análise documental, a entrevista semiestruturada e o questionário.

Portanto, a relevância da pesquisa está na necessidade de discussões acerca do AEE, bem como na demanda por reflexões sobre a importância desse atendimento aos alunos com deficiência. Assim, esperamos que este estudo favoreça a reflexão/ação a respeito dos saberes essenciais para a organização e implantação do AEE, objetivando uma análise crítica de seus paradigmas, que durante décadas trabalhou com a ideia de apoio e reforço.

É imprescindível destacar que esta pesquisa foi autorizada pela Secretaria Municipal de Educação de Uberlândia (SME) para a sua realização no Núcleo de Apoio às Diferenças Humanas (NADH) e escolas municipais. Além disso, foi submetida ao Comitê de Ética em Pesquisa (CONEP), por meio da Plataforma Brasil, em que disponibilizamos o projeto, que foi encaminhado pela plataforma para avaliação do Comitê de Ética e Pesquisa da Universidade Federal de Uberlândia (CEP/UFU), sendo aprovada e tendo recebido o número 33185014.0.0000.5152, que é o Certificado de Apresentação para Apreciação Ética (CAAE). 


\section{A Educação Especial e o AEE: construções e reconstruções paradigmáticas}

A Educação Especial, tradicionalmente, caracterizou-se como atendimento às pessoas com deficiência com caráter substitutivo ao ensino ministrado na escola regular, mediante a criação de instituições especializadas, escolas especiais e classes especiais. Esse fato se constituiu historicamente, pois as ações inadequadas com relação à participação das pessoas com deficiência na escola regular sempre foram demarcadas por um grupo "moral e socialmente" determinado como "tipo ideal” (AMARAL, 1995). A sociedade aponta o que é fora do "normal", ${ }^{3}$ ou seja, a condição desviante da pessoa em relação à maioria que está dentro dos padrões "ditos normais", para diferenciar e cada vez mais marcar o indivíduo.

É preciso diferenciar para compreender melhor. Há que separar para possibilitar a compreensão. Mas que diferenciar e separar há que conhecer o "divisor de águas" entre o normal e o anormal, entre o desvio e o não desvio, entre o "legítimo" e o "ilegítimo" [...] Oscila-se, portanto, entre uma patologia do indivíduo e uma patologia social (AMARAL, 1995, p. 26-29).

Portanto, em ambientes escolares excludentes, segundo Ropoli et al. (2010, p. 7), a identidade "normal" é sempre tida como natural, que precisa ser generalizada e que é positiva em relação aos demais, "e sua definição provém do processo pelo qual o poder se manifesta na escola, elegendo uma identidade específica através da qual as outras identidades são avaliadas e hierarquizadas".

É nesse cenário de conflitos e de poder nas relações que se precisa cada vez mais investir de fato na escola, e na organização/oferta dos serviços necessários para atender aos alunos público-alvo da Educação Especial presentes nesse espaço. Assim, a concepção de escola inclusiva, assegurada em todos os documentos legais e orientadores sobre a educação do nosso país, fundamenta-se no reconhecimento das diferenças humanas e na aprendizagem centrada nas potencialidades dos alunos.

Diante de todos os debates, reflexões e questionamentos, surge a Política Nacional de Educação Especial na Perspectiva da Educação Inclusiva (2008), um marco histórico e político para todo o País. Desse modo, para a efetivação dessa política, de fato os sistemas de ensino de todo o País precisam organizar "as condições de acesso aos espaços, aos recursos pedagógicos e à comunicação que favoreçam a promoção da aprendizagem e a valorização das diferenças, de forma a atender as necessidades educacionais de todos os alunos" (BRASIL, 2008, p. 12).

${ }^{3}$ Normal no sentido que se enquadra nos padrões definidos pela sociedade, no caso específico deste trabalho que não tenha deficiência e/ou outros comprometimentos. 
Dessarte, essa política também apresenta bem definido o seu público-alvo, uma vez que historicamente cabia à Educação Especial alunos com deficiência ou os que não se adequassem/enquadrassem à estrutura rígida dos sistemas de ensino (dificuldades de aprendizagem, dislexia, transtorno déficit de atenção, entre outros). Dessa forma, os alunos público-alvo da Educação Especial, a partir da política de 2008, são os alunos com deficiências (física, visual, intelectual e surdez), transtornos globais do desenvolvimento (TGD) e altas habilidades/superdotação (AHS).

O AEE, então, um dos serviços da Educação Especial, tem como função "identificar, elaborar e organizar recursos pedagógicos e de acessibilidade que eliminem as barreiras para a plena participação dos alunos, considerando suas necessidades específicas" (BRASIL, 2008, p. 10). Em virtude de esse atendimento não ser de caráter substitutivo à escolarização, as atividades desenvolvidas diferenciam-se das trabalhadas em sala de aula comum. Assim, esse atendimento complementa e/ou suplementa a formação dos alunos com o objetivo de desenvolver a sua autonomia e independência dentro e fora da escola. Para tanto, há que se verificar a responsabilidade dos Municípios e Estados para a implantação do AEE, a Sala de Recurso Multifuncional (SRM), a acessibilidade (arquitetônica e pedagógica) e, principalmente, a formação dos professores.

Logo, é preciso analisar, conforme afirma Imbernón (2009), o que funciona na educação, o que temos que abandonar, o que é necessário construir e/ou reconstruir diante do velho. "É possível modificar as políticas de formação permanente do professorado? Como as mudanças atuais repercutem na formação do professorado"? (IMBERNÓN, 2009, p. 18). São questões como essas que precisam perpassar o planejamento de ações na elaboração de uma formação continuada/permanente que atenda às reais necessidades dos professores, estando relacionada à sua vivência nos seus contextos de atuação.

Não há como negar que o problema parece estar na maneira como vem sendo gerida a formação inicial e contínua no Brasil, formação esta que, em muitos casos, se completa num curto período e superficialmente, e também muitas vezes as condições de trabalho nas escolas são, frequentemente, desfavoráveis à participação e à capacitação contínua da sua equipe de professores. Somadas a isso, as mudanças vertiginosas pelas quais a sociedade vem passando, seja no campo tecnológico, nas mudanças da estrutura familiar, o compartilhamento acelerado e desenfreado das informações, têm influenciado diretamente na atuação do professor e, consequentemente, a sua formação continuada precisa ser repensada e ressignificada. 
Não podemos deixar de enfatizar que a formação continuada/permanente dos professores deve considerar o desenvolvimento atitudinal ${ }^{4}$ e emocional do professor. Se o professor se encontrar desmotivado, consequentemente sua atuação estará comprometida. O professor necessita de uma formação que o auxilie a lidar com as questões emocionais e com a sua prática pedagógica cotidiana diante das situações adversas no contexto de sua sala de aula e da escola.

Voltando para o discurso da participação dos alunos público-alvo da Educação Especial na escola comum/regular, muito há que se pensar na formação e atuação desse professor, quer seja da sala/classe comum, quer seja do AEE, sem dizer que suas emoções e atitudes demonstram qual é o seu olhar para o contexto educacional vivido e para os seres humanos que ali estão. A atenção às diferenças no contexto da escola e a compreensão de que reconhecer as diferenças e/ou ter uma escola inclusiva é contar com a presença de alunos com deficiência, TGD e AHS na escola é um equívoco sério e que precisa ser esclarecido. É claro que o trabalho com os alunos público-alvo da Educação Especial requer toda uma estrutura e a oferta de serviços específicos no atendimento às necessidades da oferta do AEE na escola.

Seguindo essa linha de raciocínio, a formação continuada dos professores, tanto do AEE quanto da sala/classe comum, precisa apresentar a concepção de que "[...] classificar alguém como diferente parte do princípio de que o classificador considera existir outra categoria que é a de normal, na qual ele naturalmente se insere” (RODRIGUES, 2006, p. 305). Aqui reside a grande dificuldade de os professores reconhecerem os alunos com deficiência e enxergarem suas potencialidades.

Contudo, mais do que a efetivação de uma política, há que pensar na mudança do olhar das pessoas e nas ações empreendidas ainda com caráter de imposição e obrigação. Os dispositivos legais estão postos, as diretrizes a serem seguidas definidas, mas, para além do que o papel vê, há que pensar e refletir sobre quem executará/construirá/implementará/oportunizará essas mudanças, o ser humano, e para isso requer mudança de valores, concepções e atitudes.

\section{Para além do senso comum: percurso metodológico}

Ao se pensar nesta pesquisa e por se tratar especificamente de uma pesquisa voltada para a educação, chegamos à abordagem qualitativa de caráter descritivo e analítico. Não podemos deixar de enfatizar que, quando fizemos essa escolha, compreendemos que essa

4 "Entende-se aqui atitude como sentimento de disposição ou predisposição, conseguido e organizado através da experiência, que exerce uma influência específica sobre a resposta da pessoa ao contexto" (IMBERNÓN, 2009, p. 98). 
abordagem parte do princípio de que as impressões dos atores envolvidos nesse processo são primordiais, segundo Lankshear e Knobel (2008).

Como explicitado que a pesquisa foi de caráter descritivo analítico, Gil (2008) explica que esse tipo de pesquisa tem como objetivo principal a descrição das características de um dado objeto (população ou fenômeno) e as relações com suas diferentes variáveis. Para tanto, os dados coletados na pesquisa foram a análise documental, entrevista e questionário.

Primeiramente, a coleta de dados começou pela análise documental referente aos materiais escritos disponibilizados pelo $\mathrm{NADH}$, o primeiro universo da nossa pesquisa. A análise documental contribuiu com a pesquisa, pois analisamos o histórico do NADH, o quadro de escolas e os alunos atendidos no AEE, a Instrução Normativa 001/2011 que regulamenta o atendimento nas escolas, bem como os documentos norteadores do AEE no Brasil, tais como: a Política Nacional de Educação Especial na Perspectiva da Educação Inclusiva de 2008, o Decreto 7.611/2011 que dispõe sobre a Educação Especial e o AEE, e a Resolução 04/2009, que institui as diretrizes operacionais para o AEE na Educação Básica, modalidade Educação Especial, os referenciais teóricos divulgados/distribuídos/disseminados pelo MEC em todo o País. A análise documental e/ou textual, segundo Lankshear e Knobel (2008), deve estar coerentemente relacionada com a perspectiva teórica usada pelo pesquisador e, consequentemente, com o problema de pesquisa apresentado.

Após a análise documental, lançamos mão da entrevista semiestruturada, aplicada na coordenação do NADH, nos anos de 2005 a 2012, e depois na coordenadoria atual que começou a atuar em 2013. A opção pela entrevista semiestruturada se deu pelo fato de que, conforme afirma André (1996, p. 34), “a entrevista semiestruturada é um procedimento interessante por possibilitar abertura entre o pesquisador e o entrevistado, pois favorece respostas espontâneas". Com certeza, todas as informações prestadas contribuíram com a pesquisa e para análise dos demais dados coletados.

Com o intuito de ampliar a pesquisa, aplicamos questionários, com o objetivo de verificar a compreensão dos professores que ofertam o AEE nas escolas e dos professores que recebiam esse atendimento para seus alunos. Para a escolha das quatro escolas pesquisadas, foram adotados dois critérios: pertencerem aos setores de organização do governo atual (Leste, Oeste, Norte e Sul), uma vez que o setor central não foi escolhido por contar apenas com duas escolas de Ensino Fundamental; e contarem com o maior número de alunos atendidos no AEE de $1 .^{\circ}$ ao $5 .^{\circ}$ ano. Adotamos o uso do questionário, pois, de acordo com Gil (1991), o uso deste é parte das pesquisas descritivas que visam a conhecer características do fenômeno estudado. 
Constituíram como sujeitos de pesquisa dez pessoas, sendo duas do NADH (coordenadora anterior do setor - 2005 a 2012 - e a coordenadora atual - 2013 aos dias atuais), e oito professores, sendo quatro do AEE e quatro da classe comum. Seguem os quadros com o perfil dos atores da pesquisa:

Quadro 1 - Perfil dos coordenadores do NADH

\begin{tabular}{|c|c|c|c|}
\hline Identificação & Gênero/Idade & Formação & Experiência no AEE \\
\hline $\begin{array}{c}\text { Coordenadora } \\
1\end{array}$ & $\begin{array}{l}\text { Feminino, } \\
50 \text { anos }\end{array}$ & $\begin{array}{l}\text { Graduação em Pedagogia } \\
\text { Especialização em AEE e } \\
\text { Especialização em } \\
\text { Psicopedagogia }\end{array}$ & 22 anos \\
\hline $\begin{array}{c}\text { Coordenadora } \\
2\end{array}$ & $\begin{array}{l}\text { Feminino, } \\
\text { 52anos }\end{array}$ & $\begin{array}{c}\text { Graduação em Geografia } \\
\text { Especialização em AEE e } \\
\text { Especialização em Geografia }\end{array}$ & 19 anos \\
\hline
\end{tabular}

Fonte: Autores

Quadro 2 - Perfil dos professores de AEE das escolas

\begin{tabular}{|c|c|c|c|}
\hline Identificação & Gênero/Idade & Formação & Experiência no AEE \\
\hline PAEE 1 & $\begin{array}{c}\text { Feminino, } \\
\text { Escola Leste } 40 \text { a 50 anos }\end{array}$ & $\begin{array}{c}\text { Graduação em Pedagogia } \\
\text { Especialização em Educação } \\
\text { Especial e Psicopedagogia }\end{array}$ & $\begin{array}{c}\mathbf{1 6} \text { anos, como } \\
\text { professora. }\end{array}$ \\
\hline PAEE 2 & $\begin{array}{c}\text { Feminino, } \\
\text { Escola Oeste }\end{array}$ & $\begin{array}{c}\text { Graduação em Pedagogia } \\
\text { Especialização em Educação } 50 \text { anos } \\
\text { Especial e Psicanálise e } \\
\text { Educação }\end{array}$ & $\begin{array}{c}\mathbf{2 0} \text { anos, como } \\
\text { professora. }\end{array}$ \\
\hline PAEE 3 & $\begin{array}{c}\text { Feminino, } \\
\text { Escola Norte }\end{array}$ & $\begin{array}{c}\text { Graduação em Pedagogia } \\
\text { de } 40 \text { a 50 anos } \\
\text { Ensino e Aprendizagem }\end{array}$ & $\begin{array}{c}\mathbf{2 0} \text { anos, como } \\
\text { professora. }\end{array}$ \\
\hline PAEE 4 & Feminino, & $\begin{array}{c}\text { Graduação em Pedagogia } \\
\text { Especialização em } \\
\text { Escola Sul }\end{array}$ & $\mathbf{7}$ anos, como pedagogag. \\
\hline
\end{tabular}

Fonte: Autores

Quadro 3 - Perfil dos professores da classe comum das escolas

\begin{tabular}{|c|c|c|c|}
\hline Identificação & Gênero/Idade & Formação & $\begin{array}{c}\text { Experiência como } \\
\text { professora }\end{array}$ \\
\hline $\begin{array}{c}\text { PCC 1 } \\
\text { Escola Leste }\end{array}$ & $\begin{array}{c}\text { Feminino, } \\
\text { de } 40 \text { a 50 anos }\end{array}$ & $\begin{array}{c}\text { Graduação em Pedagogia } \\
\text { Especialização em } \\
\text { Psicopedagogia }\end{array}$ & Mais de 20 anos \\
\hline PCC 2 & Feminino, \\
Escola Oeste & de 40 a 50 anos & $\begin{array}{c}\text { Graduação em Pedagogia } \\
\text { Especialização em } \\
\text { Psicopedagogia }\end{array}$ & Mais de 20 anos \\
\hline PCC 3 & Feminino, & $\begin{array}{c}\text { Graduação em Pedagogia } \\
\text { de 30 a 40 anos }\end{array}$ & Especialização em Supervisão \\
Escola Norte & Delar 15 anos & Mais de 20 anos \\
\hline PCC 4 & Feminino, & $\begin{array}{c}\text { Graduação em Normal Superior } \\
\text { Especialização em Supervisão } \\
\text { Escolar }\end{array}$ & \\
\hline
\end{tabular}

Fonte: Autores 
Somos conscientes de que a Educação Especial na Perspectiva da Educação Inclusiva ainda está em processo de construção/reconstrução em todas as escolas do País. Nesse contexto, a pesquisa que realizamos apresentou o cenário das escolas da rede municipal de Uberlândia, com relação à oferta do AEE, a partir do olhar dos atores principais envolvidos na implantação de todo esse processo: os professores.

Com esse intento, na coleta de dados realizada por meio da análise documental, das entrevistas e dos questionários, foi possível fazer a correlação de todos os aspectos dados/apresentados pelos atores da pesquisa. Assim, a partir da análise de conteúdo (AC) das diferentes fontes de coleta de dados, o primeiro passo foi organizar as informações e categorizá-las.

A primeira categoria referiu-se à história da Educação Especial no município de Uberlândia, na esfera municipal, objetivando descrever como o atendimento aos alunos com deficiência iniciou-se nas escolas da rede municipal, bem como descrever e analisar o processo de implantação do AEE a partir da Política de Educação Especial na Perspectiva da Educação Inclusiva (2008) e, consequentemente, os demais documentos/referenciais teóricos que dão as diretrizes para a organização do AEE no contexto da escola regular.

A segunda categoria foi relacionada à visão dos professores sobre o AEE e o NADH relatando os olhares sobre o AEE, bem como a compreensão da função do NADH nesse processo de construção/reconstrução do atendimento voltado aos alunos com deficiência.

A terceira categoria tratou da Sala de Recurso Multifuncional (SRM) e da acessibilidade arquitetônica e pedagógica da escola, descrevendo e analisando como está organizada a sala para o atendimento, assim como está a acessibilidade dos alunos, seja no AEE e/ou em sala de aula e nos demais espaços da escola, assegurando o acesso arquitetônico e o acesso pedagógico dos alunos aos conteúdos trabalhados no contexto escolar.

A quarta categoria foi referente à formação dos professores, quer seja a inicial, quer seja a continuada (ofertada pelo NADH), com o intuito de compreender como os profissionais têm acompanhado essa transição da escola e, acima de tudo, como têm se formado e se instruído para o atendimento desses alunos, seja no AEE ou em classe comum.

Por fim, na quinta categoria, apresentamos os entraves na/para atuação segundo os profissionais com o intuito de dar voz às observações sobre as facilidades e limitações de ações no trabalho com os alunos com deficiência, seja no AEE, na sala de aula ou em uma função mais ampla de implantação e acompanhamento do trabalho da Educação Especial na escola regular. 


\section{O AEE no município de Uberlândia: os diferentes vieses, os caminhos trilhados e as ressignificações necessárias}

Por décadas, a perspectiva de educação que imperou para os alunos da Educação Especial foi a exclusão, passando por processos desde a segregação, assistencialismo, integração, até à luta pela tão aclamada/chamada inclusão. Portanto, como é possível atender aos alunos da Educação Especial na escola comum/regular? O que é necessário articular nesse espaço para que esses alunos sejam atendidos em suas especificidades? Houve, então, nesse percurso, as salas especiais dentro da escola, as aulas de apoio e reforço nos horários da aula, como tantas outras formas que cada escola encontrou para atender a essa demanda. Hoje, podemos contar com o AEE como uma modalidade de ensino.

É inegável que as ferramentas estão aí, para que as mudanças aconteçam e para que reinventemos a escola, "desconstruindo" a máquina obsoleta que a dinamiza, os conceitos sobre os quais ela se fundamenta, os pilares teóricometodológicos em que ela se sustenta (MANTOAN, 2003, p. 52).

Nesse sentido, a pesquisa realizada objetivou apresentar e analisar o processo de implantação do AEE nas escolas da rede municipal de Uberlândia, a partir das discussões acerca da Política Nacional de Educação Especial na Perspectiva da Educação Inclusiva e dos demais documentos elaborados e construídos diante dessas orientações. Os pontos que destacamos na finalização da pesquisa são os que denominamos de problemáticas e proposições. Problemáticas no que tange aos dados coletados que nos apontaram questões importantes que precisam ser revistas e que têm dificultado o trabalho do AEE nas escolas e, consequentemente, a oferta de uma educação com equidade e qualidade para os alunos da Educação Especial; proposições que são sugestões de encaminhamentos a partir dos problemas detectados e que estão coerentes com o embasamento teórico apresentado ao longo da pesquisa.

Inicialmente, a pesquisa apresentou-nos que existe uma ausência de articulação entre a assessoria do Ensino Fundamental e o setor da Educação Especial (NADH). Esse fator ficou claro na fala das duas coordenadoras, pois ambas afirmaram a desarticulação política em muitos momentos, o que reflete diretamente no trabalho dentro das escolas. Portanto, a equipe diretiva da SME precisa articular, entre os setores, as ações que serão empreendidas para a organização das escolas e do AEE, visto que o aluno não é apenas um número, mas um ser humano que faz parte da instituição e que tem assegurado como direito o AEE, logo, a oferta é dever da escola, e a questão não é apenas aceitar esses alunos, mas reconhecê-los nas diferenças que lhes são peculiares. 
Constatamos, assim, que de nada adianta os professores da sala/classe comum e do AEE responsabilizar uns aos outros pelo trabalho acontecer ou não, pois cada um deles tem papel fundamental no processo de ressignificação da escola, que passa, primeiramente, pelo reconhecimento dos seus alunos, e não apenas respeito e tolerância. Para que tenhamos uma escola de fato aberta às diferenças, é necessária uma articulação em que não se separe sala/classe comum e AEE, pois um complementa o outro na ação conjunta para o sucesso do aprendizado dos alunos.

Para Ropoli et al. (2010), o desafio de fazer esse ensino de qualidade está no envolvimento de todos "os que compõem um sistema educacional. Um ensino de qualidade provém de iniciativas que envolvem professores, gestores, especialistas, pais e alunos e outros profissionais que compõem uma rede educacional" (ROPOLI et al., 2010, p. 10). Para tanto, não há como negar que o atendimento das pessoas com deficiência na escola requer redes de apoio que passam pela Educação Especial e os seus serviços ofertados.

Outro problema detectado foi a falta de articulação política entre a SME e as demais secretarias, uma vez que a educação trata dos aspectos pedagógicos, extrapolando, quanto ao seu trabalho, aspectos de saúde e assistência social. Mais uma vez, fica claro que as redes de apoio precisam ser construídas entre as escolas e a sociedade, pois, ao se falar de inclusão no sentido filosófico e epistemológico, as pessoas precisam ser reconhecidas e valorizadas nos diferentes espaços de convivência. Entretanto, se a escola, que é uma das frentes de formação de pessoas, ainda está tão arraigada a preceitos conservadoristas dos ideais passados, contaremos com uma instituição preconceituosa e uma sociedade cada vez mais excludente.

Ao abordarmos a questão da desarticulação política, outros problemas identificados podem estar diretamente relacionados a essa problemática, pois as ações no âmbito macro interferem, e muito, no âmbito micro, no caso, as escolas. A pesquisa mostrou, então, que, assim como há uma desarticulação da equipe diretiva, existe uma falta de interação entre professores do AEE e da sala/classe comum, fato que ficou bem marcado nas falas dos professores que tentam justificar as suas próprias dificuldades como se o problema estivesse ora no AEE, e/ou ora na sala/classe comum. Logo, se a assessoria do Ensino Fundamental e o NADH estabelecessem uma parceria na condução da proposta filosófica das escolas e, consequentemente, na organização das práticas pedagógicas desses professores, a escola tornar-se-ia cada vez mais inclusiva.

Mas nada será conseguido se não se alterarem as condições existentes nas escolas e as políticas públicas em relação aos professores. É inútil apelar à reflexão se não houver uma organização das escolas que a facilite. É inútil reivindicar uma formação mútua, inter pares, colaborativa, se a definição 
das carreiras docentes não for coerente com este propósito (NÓVOA, 2009, p. 21).

Dessarte, quando os professores da sala/classe comum afirmaram que não receberam visitas dos representantes do NADH na escola, fica claro que, se este é responsável pela Educação Especial, independentemente de estar em contato ou não com esses professores, estes devem ser orientados sobre o seu trabalho em sala de aula com as diferenças, o que somente será possível se a articulação política entre os setores na SME acontecer de fato. Para isso, os setores que acompanham o trabalho nas escolas precisam estar em consonância com suas falas e proposições de ações para minimizar as barreiras para o acesso dos alunos público-alvo da Educação Especial.

A pesquisa também indicou que uma das principais barreiras para o acesso das pessoas com deficiência, TGD e AHS não são estruturais, mas atitudinais, uma vez que ao longo de todo o processo investigativo foi possível perceber as ações empreendidas para que a falta de acessibilidade arquitetônica fosse superada/sanada, seja com verba municipal, inicialmente, assim como com verbas federais. No entanto, mais do que rampas, as escolas precisam de profissionais que de fato compreendam e reconheçam as diferenças humanas como condição inerente de todo ser humano. E nas escolas municipais de Uberlândia essa questão não é diferente, mas precisa ser superada e ressignificada.

Para Sassaki (2005), uma das maiores barreiras impostas para as pessoas com deficiências, seja na escola ou na sociedade como um todo, é a atitudinal. Logo, é preciso ser garantida a acessibilidade atitudinal. Para essa quebra de preconceitos, estereótipos, discriminações, as pessoas devem se conscientizar e se sensibilizar para que possam saber conviver com a diferença.

Os resultados da pesquisa revelaram ainda que a acessibilidade arquitetônica das escolas, bem como as SRM, está a contento, porém, além das barreiras atitudinais, existem as barreiras instrumentais e procedimentais. Instrumentais porque estão relacionadas à ausência de recursos adequados ao trabalho com os alunos na escola, e procedimentais com relação a como o professor utiliza esses recursos. Inferimos que, mais uma vez, as barreiras estão nas ações e na prática pedagógica empreendidas, culminando com a necessidade de mudança de concepção e paradigma dos profissionais, o que está diretamente relacionado à formação continuada.

Portanto, os espaços escolares e sociais ainda são excludentes e requerem uma mudança atitudinal urgente e emergente para que se tornem de fato acolhedores e “inclusivos", ampliando a compreensão do que seja inclusão. O simples fato de termos alunos com deficiência nas escolas não é condição para que esse espaço seja inclusivo. Essa questão 
somente será superada e compreendida por meio de uma formação continuada coerente e relacionada com a base epistemológica que sustenta as práticas pedagógicas que impulsionarão o trabalho dos professores.

Este estudo revelou o quão séria é a questão da formação continuada, que, de acordo com os relatos dos professores, quer seja a inicial e/ou a continuada, não atende às demandas por não estar relacionada à realidade das escolas. Não podemos criticar a formação de professores, se não tomarmos uma atitude que ressignifique, urgentemente, a maneira de conceber essa formação, que não pode mais ser ofertada como "caixetinhas" para cada tipo de atuação e/ou professor. Se o município assumiu um compromisso em tornar as escolas inclusivas, precisa começar pela formação integral de TODOS os seus profissionais, indistintamente.

Dessarte, é preciso analisar, conforme afirma Imbernón (2009), o que funciona na educação, o que temos que abandonar, o que é necessário construir e/ou reconstruir diante do velho. "É possível modificar as políticas de formação permanente do professorado? Como as mudanças atuais repercutem na formação do professorado"? (IMBERNÓN, 2009, p. 18). São questões como essas que precisam perpassar o planejamento de ações na elaboração de uma formação continuada/permanente que atenda às reais necessidades dos professores, estando relacionada à sua vivência nos seus contextos de atuação.

Segundo nosso olhar, há que pensar na formação continuada dos profissionais da educação como um todo em dois momentos: a formação geral e permanente ofertada pela SME/CEMEPE, que tratará de aspectos voltados para a base epistemológica da proposta pedagógica das escolas, que está diretamente relacionada com a perspectiva inclusiva; e a formação in locus, que tratará da realidade de cada escola diante da singularidade e complexidade de cada contexto, dando voz e vez aos professores.

Por meio dessa formação, ora geral, ora específica, os professores do AEE e da sala/classe comum terão a oportunidade de compreender qual é o seu papel nesse processo formador e educativo na escola, enquanto espaço que tem por obrigação legal celebrar e reconhecer as diferenças. A interação professor do AEE e sala/classe comum só terá sentido quando a formação continuada representar as vivências cotidianas das escolas e as práticas empreendidas por esses professores para superarem os desafios diários no trabalho com os alunos público-alvo da Educação Especial.

Não poderíamos deixar de enfatizar que apenas a oferta obrigatória da formação continuada mensal para os professores do AEE, que é o caso dos profissionais das escolas da rede municipal de Uberlândia, não é garantia de que esses professores estejam compreendendo a sua função nesse atendimento. Os professores revelaram falta de 
compreensão acerca do significado do atendimento complementar e/ou suplementar no trabalho do AEE, mostraram desconhecer que não se trata de apoio e reforço e/ou substitutivo ao trabalho desenvolvido em sala/classe comum. Esse é mais um indício da fragilidade do processo de formação, pois todos os professores atuam há vários anos no AEE e disseram que frequentam os cursos ofertados pelo NADH.

\section{Considerações finais}

Constatamos, ao longo de toda a pesquisa, que o município de Uberlândia está em consonância com a legislação no que diz respeito à oferta do AEE, no entanto há muito a ser feito para que as ações sejam efetivadas na perspectiva da inclusão. A concepção integracionista da década de 1980 ainda se faz presente, a despeito do discurso da inclusão. Lógico que foram observados avanços, mas são insuficientes do ponto de vista do direito da pessoa com deficiência. Construir uma escola na perspectiva da Educação Inclusiva, bem como a oferta do AEE aos alunos com deficiência, TGD e AHS, ainda é um percurso difícil enfrentado cotidianamente pelas escolas brasileiras e, especificamente, pelas escolas da rede municipal de Uberlândia.

Contudo, lutar por espaços cada vez mais acolhedores e solidários ainda é um grande desafio para a sociedade, e nessa reinvenção encontramos a escola com toda a complexidade e singularidade que lhe é peculiar. Esperamos que por meio desta pesquisa novos estudos possam ser realizados com o intento de contribuir com a Educação Especial e com as escolas da rede municipal de Uberlândia de modo geral, que, independentemente das dificuldades enfrentadas, estão construindo a sua história e enfrentando as demandas que lhes são apresentadas. Nosso objetivo não foi dar respostas e/ou apontar soluções, mas fazer uma análise crítica do que os sujeitos de pesquisa apontaram e apresentar proposições que possam impulsionar o fazer, pois em nada nesta vida podemos dizer que temos respostas prontas e acabadas.

\section{REFERÊNCIAS}

AMARAL, L. A. Conhecendo a deficiência (em companhia de Hércules). São Paulo: Copyright, 1995.

ANDRÉ, M. E. D. A. O papel da pesquisa na formação do professor. Formação de professores: tendências atuais. São Carlos: UFSCar, 1996.

BOGDAN, R.; BIKLEN, S. Investigação qualitativa em educação. Uma introdução à teoria e aos métodos. Porto: Porto Editora, 1994. 
BRASIL. Constituição Federal da República Federativa do Brasil. Brasília, 1988.

BRASIL. Lei n. ${ }^{\circ}$ 9.394. Lei de Diretrizes e Bases da Educação Nacional. Brasília, 1996.

BRASIL. Diretrizes Nacionais para a Educação Especial na Educação Básica. Resolução n. ${ }^{\circ} 2$ CNE/CEB. Brasília: MEC/SEESP, 2001.

BRASIL. Ministério da Educação. Secretaria de Educação Especial. Política Nacional de Educação Especial na Perspectiva da Inclusão. Brasília: MEC/SEESP, 2008.

BRASIL. Ministério da Educação. Secretaria de Educação Especial. Decreto n. ${ }^{0}$ 7.611. Brasília, 2011.

GIL, A. C. Como elaborar projetos de pesquisa. São Paulo: Atlas, 1991.

GIL, A. C. Métodos e técnicas de pesquisa social. 6. ed. São Paulo: Atlas, 2008.

IMBERNÓN, F. Formação permanente do professorado: novas tendências. São Paulo: Cortez, 2009.

LANKSHEAR, C.; KNOBEL, M. Panorama da coleta de dados na pesquisa qualitativa. In: LANKSHEAR, C.; KNOBEL, M. Pesquisa pedagógica: do projeto à implantação. Tradução Magda França Lopes. Porto Alegre: Artmed, 2008. p. 149-167.

LÜDKE, M.; ANDRÉ, M. E. D. A. Pesquisa em educação: abordagens qualitativas. São Paulo: EPU, 1986.

MANTOAN, M. T. E. Inclusão escolar: O que é? Por quê? Como fazer? São Paulo: Moderna, 2003.

NÓVOA, A. Professores: imagens do futuro presente. Lisboa: Relgráfica Artes Gráficas, 2009.

RODRIGUES, D. A inclusão e educação: doze olhares sobre a educação inclusiva. São Paulo: Summus, 2006.

ROPOLI, E. A. et al. A educação especial na perspectiva da inclusão escolar: a escola comum inclusiva. Brasília: Ministério da Educação, Secretaria de Educação Especial, 2010.

SASSAKI, R. K. Inclusão: o paradigma do século 21. Revista Inclusão, SEESP/MEC, ano I, n. 1, p. 19-23, out. 2005.

SME - Secretaria Municipal de Educação. Instrução Normativa n. ${ }^{0}$ 001/2011. UberlândiaMG, 2011.

SME/NADH - Secretaria Municipal de Educação, Histórico do Programa Básico Legal Ensino Alternativo (PEA). Uberlândia-MG, 2005. 


\section{Como referenciar este artigo}

ALVES, Carla Barbosa e MIRANDA, Maria Irene. Atendimento educacional especializado na rede municipal de Uberlândia: implantação, organização e desenvolvimento. Doxa: Rev. Bras. Psico. e Educ., Araraquara, v. 21, n. 2, p. 269-284, jul./dez. 2019. e-ISSN: 2594-8385. DOI: https://doi.org/10.30715/doxa.v21i2.13100

Submetido em: 20/02/2019

Aprovado em: 20/07/2019

Publicado em: 01/08/2019 